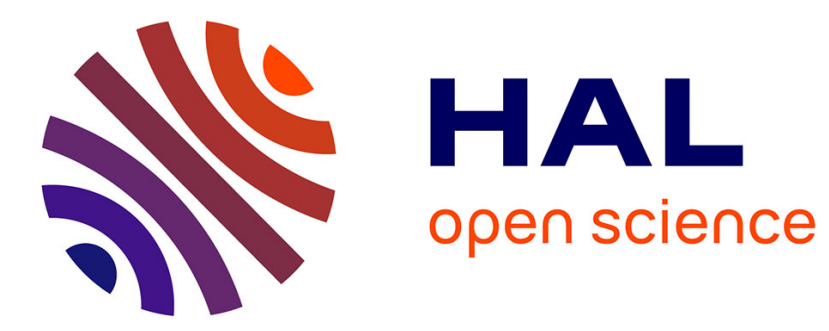

\title{
Co-operative Production Planning: Dynamic Documents in Manufacturing
}

Steinar Kristoffersen

\section{To cite this version:}

Steinar Kristoffersen. Co-operative Production Planning: Dynamic Documents in Manufacturing. IFIP International Conference on Advances in Production Management Systems (APMS), Sep 2015, Tokyo, Japan. pp.85-92, 10.1007/978-3-319-22756-6_11 . hal-01417404

\section{HAL Id: hal-01417404 \\ https://hal.science/hal-01417404}

Submitted on 15 Dec 2016

HAL is a multi-disciplinary open access archive for the deposit and dissemination of scientific research documents, whether they are published or not. The documents may come from teaching and research institutions in France or abroad, or from public or private research centers.
L'archive ouverte pluridisciplinaire HAL, est destinée au dépôt et à la diffusion de documents scientifiques de niveau recherche, publiés ou non, émanant des établissements d'enseignement et de recherche français ou étrangers, des laboratoires publics ou privés. 


\title{
Co-operative Production Planning: Dynamic Documents in Manufacturing
}

\author{
Steinar Kristoffersen \\ Møreforsking Molde AS and Molde University College \\ Postboks 21106402 Molde \\ Norway \\ steinar.kristoffersen@himolde.no
}

\begin{abstract}
This case study describes the manufacturing of advanced, highvalue maritime vessel equipment as an opportunistic, dynamic, knowledgeneedy and collaborative process, in which planning and construction is closely integrated, rather than as a repeatable physical assembly that takes place in phases, for each of which planning is pre-hoc and pre-emptive. We assert that this is one reason that the anachronistic perspective of "documents as documentation", contributes to actors' conflicting views of their project. This paper examines these difficulties, offers a theoretical examination and design implications for next generation industries to consider.
\end{abstract}

Keywords : Design and manufacturing in a collaborative setting, engineer-toorder (ETO), lean documentation, quality, IT support for industry

Many enterprises in high-income countries are bound to struggle with higher production costs than those of many less-mature, yet ambitious economies. Straight competition on identical terms is impossible. Hence a succession of process re-construction efforts has been launched in high-cost countries [1]. Most reformation programs bring together existing schemes, such as lean, mass customization and ETO (engineer-toorder), concurrent engineering and front-end loading $[2,3]$. There has been little improvement, however. Traditionally bureaucratic and vertically integrated manufacturing, with centralized planning, scheduling, and control mechanisms are not sufficiently flexible for this type of production and product-mix [4]. We find suggestions in the literature that hard problems of process planning and manufacturing control in a dynamic, distributed portfolio may possibly be solved using agent technology [4], expert systems [5] or case-based reasoning [5], etc. However, experience shows us that most businesses rely on simple software, such as spread sheets and text editors, email and databases for their manufacturing management support. As a consequence, multiple perspectives on planning, evaluation and the economy of the project arise, which reduces manageability. This paper's objective is to explicate this practice and initiate a road map ahead that may alleviate the situation. 
In the domain that pertains to this paper ratio of labor to value-creation has been relatively stable since the seventies [6], which might imply that our industry's "high value-creation knowledge networks" (cf. [7]) are less efficient than we believe. This might have to be improved shortly.

\section{Research problem}

The ability to be flexible and respond favorably to change orders is a distinguishing characteristic of the so-called "engineer-to-order" industries [8]. However, when extraneous factors such as a fall in the oil price comes into play, it turns out that this edge becomes very blunt, indeed, as customers start demanding that "flexible costs" regardless, are made "off-the-shelf". In the current paradigm, outsourcing to low-cost countries possible has contributed to make this possible as well as profitable [9]. However, when the same performance become universally available, customer do not wish to pay a premium for tradition [10]. Hence, a next step up and forward is required for European industries to survive in global competition [11].

We believe that poorly understood documentation practices have contributed to reduce innovation of the current situation. Outsourcing as a "division of labor" has often been based on insufficient specifications, incomplete planning or inaccurate estimation techniques [12], which may be hard to change, essentially, but the situation is exacerbated when documents are presented as objectively describing the state of affairs, whilst in reality they are interacted with as a type of agent [13].

Any detached and extraneous description is bound to be out of synch, inconsistent and erroneous, but this is not a problem unless it is poorly handled [14]. Members of an organization purposefully create different documents describing the same phenomena. If conflicts occur, however, the exposition of them in a technical perspective only [15], is not sufficient. Current digitization of production processes hide the coexistence of multi-perspective documentation and when retrieved, purport that they are equivalent representation of a phenomena. That is, as we shall demonstrate in this paper, when the trouble begins.

This paper proposes to treat documentation as "perspective elements". It may seem like a paradox that it thus thus rejects the objectivity of "documents as labels" in favor of a subjective, constructionist view of "documents in actor-networks", but in the transformation of our industry to a 4.0-type "internet of things", this is, we believe, exactly what is needed. Operationally, as well, we aim to demonstrate that this approach can be modelled using object-oriented techniques [16].

\section{$3 \quad$ Research methodology}

This study is based on ethnographic and participative research in one company. It is of course always a challenge to generalize from single case studies. However, the rich experience, which have been gained from taking part in more than 10 project meetings, in addition to phone calls/discussions and document exchanges per meeting and 
finally to contribute with findings, ideas and as a discussion partner in a project, do give a solid grounding for qualitative, theoretical reasoning. This research methodology, admittedly, does look broadly and pragmatically on what constitutes "data" for research purposes [17]. It represents, however, a well-known foundation for qualitative research [18].

\section{Investigation results in A Crane Company (ACC)}

The company that we have studied makes small and mid-sized (up to ca. 50 metric tons) cranes and handling systems, which can operate on depths down to 4000 meters. Typically, the cranes are used to place and recover underwater unmanned robots or excavators, that dig tranches, connect cables and pipes, etc., which are necessary infrastructure to support the oil and gas industry offshore.

Early projects in ACC were commonly termed "prototypes" and the current process is seen as one of increasing standardization. From the sales division's point of view, the predictability of the cost situation is crucial. They have to defend the price to the customer as well as the margins internally, towards their role as a profit centre in a group consisting of many engineering-oriented companies in a diverse concern.

The market connections are made locally, although the customers themselves already operate internationally and many have subsidiaries worldwide. Inevitably, as the business grows, so does the network and sales, which are made independently of geography.

There are clearly many rational reasons to outsource industrial production from high-cost countries, which are usually near to the affluent market and its ambition to innovate, to low-cost countries offshore, which cannot market and sell their skills in an integrated and packaged product. Repetitive or at least voluminous, man-hour intensive and burdensome parts of the manufacturing process, will still be decisive parts of large-scale industrial projects. The solution for ACC has been to stop doing manufacturing and and specialize instead on sales, design, engineering, integration and commissioning. Steel work, therefore, is outsourced. Engines and pumps are procured, as is the control system and drives. Electrical systems design, however, is mainly carried out locally.

The following recount explains the procedure of contracting and building an ETO offshore crane, together with its multifarious documentation practices.

\subsection{The go-ahead decision}

After initial contact with a customer and preliminary information exchange concerning the scope of the project, the VP of the offshore division calls a go-ahead board meeting to make the decision about bidding. The ambition has to be commercially sound, which in this context means a solid 15\% margin on the total cost of sales.

The decision is tricky, since there are many variables, especially connected to the ratio of value created through labour vs. procurement. For many suppliers to the offshore industry, it has been treated as a common fact that outsourced and procured 
parts of a project typically constitute $80 \%$ of the value created. If the parts were standardized or easily available, the decision to build a 1 million GBP crane, if it comprised 800000 GBP of parts and only 200000 of management and engineering work at home, to produce a profit of 150000 would be relatively transparent, albeit hard to achieve. It is, however, neither the case that the first 800000 are risk-free, nor that the 200000 in "knowledge work" are fixed, predictable or even particularly "manageable" as we shall show below. We put forward that one of the reasons is the way in which documents are used as documentation, paradoxically a role for which they seem wholly unsuited.

\subsection{Assertions about a procurement-centric process}

The market situation is dynamic, with oil prices governing much of what the customers on the one hand know or think they need and are willing to pay, on the other. One aspect of the current conjunctures is that the pioneering spirit of the oil \& gas sector, which has dominated for the past 15 years, have created a steady increase in demand for capacity, i.e., ships, cranes, rigs and therefore engineering work volume connect to the production of steel units and structures. Sales, design and engineering, on the other hand, which we have called knowledge work, is crucial to every project, but this intellectual capacity is rather more "flexibly available" in a way that steel work is not.

First assertion: Affluent economies educate technical engineers and accountants steadily. They take well-paid, salaried jobs mainly, which in the welfare state-models in Europe entail relatively little risk. Therefore, although companies think they struggle to find the best people and certainly would have liked to have to pay them less, they are not strongly limiting factors.

Second assertion: Pertaining somewhat to the nature of intellectual capacity as a non-limiting factor as well, is the inherent ability of knowledge work, especially in the consulting nature that dominates the market in an upward conjuncture, to be available at "super capacity", or in another less euphemistic term, over-booked. This entails that the design team might quite simply not be as available as the project needs them, due to other competing and sometimes conflicting assignments.

Third assertion: As the physical labour and manipulation of materials, which require production facilities and workshops have been "offshored", the threshold of establishing competing businesses is low. Typically, consultants, engineers and sales staff need only a laptop and a mobile phone, before they are can operate. This means that a profitable area of operation will soon be saturated with equally skilled and motivated actors, who put commercial pressure on each other.

Together these observations mean that there is much demand in the "front end" (from customer trough sales and design), whose conceptual products cannot easily be met by simply turning up the intensity of supplies from factories that make physical goods. Engineering is the bridge between design and procurement, and its interface to the factory means that it often ends up being a bottle-neck. When all projects are "urgent" and many offer to take them on, the middle-tier components suppliers, which are ETO, becomes a victim of customers who can always go elsewhere and suppliers 
who know that the ETO-companies inevitable come back to them, because there is no other easily available alternatives. Thus, when prices are transparent in an international market (everybody can call and get a quote), downwardly static and upwardly mobile, as a consequence there is no profit easily won for the ETO companies in terms of putting a margin on top the goods that they buy.

Fourth assertion: There are a growing number of designers and engineers who due to the specialized and reductionist nature of the distributed manufacturing processes do not have any hands-on experience with production as such. Hence, they depend on their own suppliers for integration and feedback on the designs they have made. Drawings are frequently incomplete or erroneous, at least in the perspective of what may be manufactured in a streamlined fashion.

Fifth assertion: When physical production facilities, such as ship yards, welding stations, rollers and forges are physical limiting production factors, at the same time as optimism is creating a drive to invest in new project (a trend that has turned, just recently, but never influenced this case), investors may want to put money into projects just to get them going, and secure their slot on the production conveyor belt, as it were. During the year or so that an advanced offshore or seismic vessel is under production, thus, it may be modified many times due to change of demand, new ideas or owners and the plans for future contracts, which have still to be negotiated. This is the business opportunity and uniqueness indicator of the ETO as well, and probably the main reason they are even still in business. They can and will change their designs to accommodate new requests and change orders from the customer in a way that larger set-ups abroad have not been able to.

\section{The ubiquitous spreadsheet}

In all stages, front-end as well as back-end reporting, the company relies on spreadsheets in various formats and designs (numbered below as i)-viii)). The sales people use it to create i) a preliminary parts + work overview, to indicate how much of a margin the project may be able to fetch in terms of profit margins. This is also used to produce an offer to the customer. The go-ahead-decision ii) revises and expands the simple set-up, with the iii) offer made to the customer as a "ceiling" idea of how much the cost of parts plus work and margins should be.

This is where the first observable set of opportunistic-dynamic strategies connected to documents (as-such) become manifest. The first document (i)) is created as the technical division feeds in experienced-based numbers of the number of hours and thus the cost, of the engineering, integration and commissioning. The numbers are still uncertain, because the exact organization of activities within each of these functional areas is variable according to which sub supplier is going to be picked. This is not known for certain at this stage. Some suppliers include the work needed to do the FAT (Factory Acceptance Test) and others do not. Some turn out to need a lot of support from the engineering team. With margins like we have indicated, of (in the order of) $100000 \mathrm{GBP}$ (which corresponds to 1000 hours from a budget of work that typically sums of to 3000 hours), this is a vulnerable situation. Depending on the sub 
supplier alternatives that exist, therefore, several variants of this "go-ahead" spreadsheet (ii)) are created. During the discussions (and certainly before), variables are adjusted and tuned in order to see if it is at all possible to create viable project. If it is accepted, a bid is made (iii)), and hopefully won.

The accounting budget (another spreadsheet iv, Fig. 1), eventually pasted into or attached with a formal letter) is then made and passed on to cost centre management, in order for them to know what to expect from the project. This is the most formal so far, and it represents the official view of the cost and risk of the project, and finally, the profit it is going to offer to the company.

The project manager, on the other hand, in parallel with this process, has already started looking at specifically which sub suppliers are willing, capable and available to offer the best combination of work capacity, skills, courage and physical location of the company and their facilities. In addition, they usually need to have validated (pre-qualified) working relations with the customer as well. This spreadsheet variant (v)) is worked out in close collaboration with the procurement officer responsible for the project. Next, one spread sheet is created to account for the orders that are placed of parts, with currency risk, volumes and discounts analysed and accounted for (vi)). This spreadsheet, which is an export from the accounting system (part of the company's ERP (Enterprise Resource Planning) system) may have thousands of lines, for which generally a "Pareto-principle" of 20/80 applies: The 20 topmost- $\%$ accounts for $80 \%$ of the cost. In the same format, but separately, parts confirmed and delivered are accounted for (vii)). Finally, accounting keeps track of the hours worked (viii)).

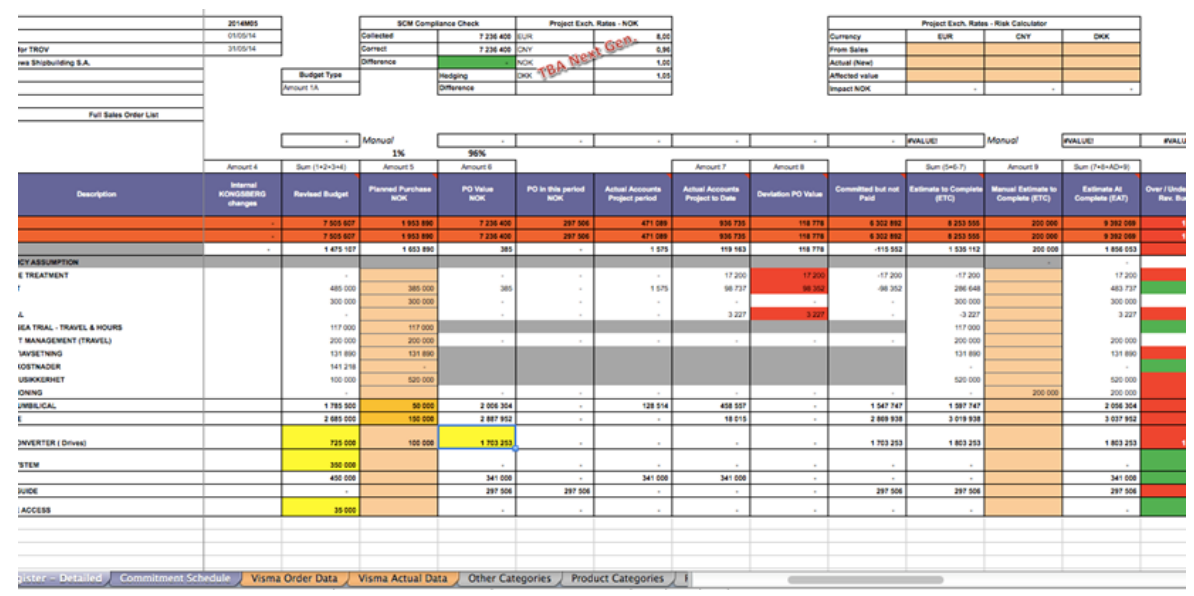

Fig. 1. Final sales/profit calculations of ACC for project $\mathrm{P}$

The result is that 6-8 different spreadsheets in two to three different formats and systems account for overlapping information, and is used in parallel by people who are working in the same project put from different points of responsibility 


\section{Digital manufacturing: a concept for dynamic design}

Design in most senses is clearly already dynamic. Its processes and outcomes can and will be changed. It is forward moving and creative. Hence it is also open-ended and expansive. "Front-end loading" relies on the assumption that all current and future dimensions can be fully explored and dealt with. Usually, they cannot.

Design captures experiences and evaluates previous drafts. The trouble is that when they are embedded into design, this new design rationale tends to be forgotten [19]. Hence, when the next problem of a similar kind is addressed, designers tends to start from the original "template", which is either completely from scratch or an anticipation of needs, which is lacking recent practical experiences that might have been embedded.

Therefore, we suggest challenging the current notion of design, which entails going from idea to product, by "inverse conceptualization", which would be to start from finished, well-known and functional products, which are the re-engineered step-bystep, in a backwards fashion, through all previous versions, releases and assembly steps, in a collaborative and problem-solving process. Clearly this cannot replace "standard design", but may complement it.

Another design-approach might be to start from a library of exceptions, deviations and previous recoveries, to look for enhancements and extensions. Products for reengineering as well as exceptions and experiences might be documented in an advanced, branch-oriented and snapshot-preserving version management system (similar to GitHub) for software.

This way of working dynamically and experience-based with design should aim to move the decoupling point as far along the production timeline as possible. There is no real product designed until it has been built. Similarly, documents should be seen as representations of ambition and a decision-making agenda, rather than snapshots of complete state. Documents are not managed, instead they manage, fit, force and frame processes. Each data element ought then to be versioned and new snapshots made every time one is requested. The planning and control of manufacturing may thus become a data-driven dynamic design science.

\section{$7 \quad$ Acknowledgments}

The financial support of VRI Møre \& Norway is appreciatively acknowledged, as well as the willingness of ACC to explore this set of ideas within a project that first and foremost aimed at reducing the cost of building cranes. We would especially like to thank managers, engineers and administrators in ACC who spent extra time in meetings and dialog with the author and other researches. 


\section{$8 \quad$ References}

1. Ekstedt, E., A New Division of Labour: The "projectification" of working and industrial life. Building Anticipation of Restructuring in Europe. Edited by M.-A. Moreau, S. Negrelli, P. Pochet. Bruxelles: Peter Lang, 2009: p. 31-54.

2. King, J.P. and W.S. Jewett, Robustness Development and Reliability Growth: Value Adding Strategies for New Products and Processes. 2010: Pearson Education.

3. Rocha, H.M., C.N.d.A. de Souza, and D.F. dos Santos Filho, Mass Customization Enablement Through Lean Design \& Set-Based Concurrent Engineering Application. Journal of Operations and Supply Chain Management. 7(2): p. 124-139.

4. Shen, W., et al., Applications of agent-based systems in intelligent manufacturing: An updated review. Advanced engineering INFORMATICS, 2006. 20(4): p. 415-431.

5. Choy, K.L., W. Lee, and V. Lo, Design of an intelligent supplier relationship management system: a hybrid case based neural network approach. Expert Systems with Applications, 2003. 24(2): p. 225-237.

6. Froud, J., et al., Financialization across the Pacific: Manufacturing cost ratios, supply chains and power. Critical Perspectives on Accounting, 2014. 25(1): p. 46-57.

7. Camarinha-Matos, L.M. and H. Afsarmanesh, Collaborative networks: Value creation in a knowledge society. Knowledge enterprise, IFIP, 2006. 207: p. 26-40.

8. Grabenstetter, D.H. and J.M. Usher, Developing due dates in an engineer-to-order engineering environment. International Journal of Production Research, 2014. 52(21): p. 6349-6361.

9. Hummels, D., Transportation costs and international trade in the second era of globalization. The Journal of Economic Perspectives, 2007: p. 131-154.

10. Venkata, S., et al., What future distribution engineers need to learn. IEEE Transactions on Power Systems, 2004. 19(1): p. 17-23.

11. Brettel, M., et al., How virtualization, decentralization and network building change the manufacturing landscape: An Industry 4.0 Perspective. International Journal of Mechanical, Industrial Science and Engineering, 2014. 8(1): p. 37-44.

12. Dwivedi, Y.K., et al., IS/IT project failures: A review of the extant literature for deriving a taxonomy of failure factors, in Grand successes and failures in IT. Public and private sectors. 2013, Springer. p. 73-88.

13. Christensen, L.R. and P. Bjorn. Documentscape: intertextuality, sequentiality, \& autonomy at work. in Proceedings of the 32nd annual ACM conference on Human factors in computing systems. 2014. ACM.

14. Massey, C., T. Lennig, and S. Whittaker. Cloudy forecast: an exploration of the factors underlying shared repository use. in Proceedings of the 32nd annual ACM conference on Human factors in computing systems. 2014. ACM.

15. Sun, D., et al. Creative conflict resolution in realtime collaborative editing systems. in Proceedings of the ACM 2012 conference on Computer Supported Cooperative Work. 2012. ACM.

16. Iivari, J., Object-orientation as structural, functional and behavioural modelling: a comparison of six methods for object-oriented analysis. Information and Software Technology, 1995. 37(3): p. 155-163.

17. Twidale, M.B., et al. Quick and dirty: lightweight methods for heavyweight research. in Proceedings of the companion publication of the 17th ACM conference on Computer supported cooperative work \& social computing. 2014. ACM.

18. Crabtree, A., et al., Ethnomethodologically informed ethnography and information system design. Journal of the American Society for Information Science, 2000. 51(7): p. 666-682.

19. Engelbart, D.C. Toward high-performance organizations: A strategic role for groupware. in Proceedings of the GroupWare. 1992. 